\title{
Chylothorax after Myocardial Revascularization with the Left Internal Thoracic Artery
}

\author{
Paulo Manuel Pêgo-Fernandes, Gustavo Xavier Ebaid, Gustavo Henrique Nouer, \\ Robinson Tadeu Munhoz, Fábio Biscegli Jatene, Adib Domingos Jatene
}

São Paulo, SP - Brazil

\begin{abstract}
A 38-year-old male underwent coronary artery bypass grafting $(C A B G)$. A saphenous vein graft was attached to the leftmarginal branch. The left internal thoracic artery was anastomosed to the left anterior descending artery $(L A D)$. The early recovery was uneventful and the patient was discharged on the 5th postoperative day. After three months, he came back to the hospital complaining of weight loss, weakness, and dyspnea on mild exertion. Chest $X$-rays showed left pleural effusion. On physical examination, a decreased vesicular murmur was detected. After six days, the diagnosis of chylothorax was made after a milky fluid was detected in the plural cavity and total pulmonary expansion didnot occur. On the next day, both anterior and posterior pleural drainage were performed by videothoracoscopy, and prolonged parenteral nutrition (PPN) was instituted for ten days. After seven days the patient was put on a low-fat diet for 8 days. The fluid accumulation ceased, the drains were removed and the patient was discharged with normal pulmonary expansion.
\end{abstract}

Chylothorax is characterized by the leakage of chyle into the pleural cavity. This condition may have several etiologies and be classified as congenital, traumatic, obstructed or spontaneous ${ }^{1}$.

The first posttrauma chylothorax was reported by Quinke in 1875, but it was Blalock who first described this entity as a complication of surgery in $1936^{2}$.

The Chylothorax is a recognized complication of intrathoracic surgery with an incidence of 0.25 to $0.50 \%$ reported in the international literature. On the other hand, its occurrence after $\mathrm{CABG}$ is extremely rare ${ }^{1,5}$.

We haven't found any report of chylothorax as a complication ofCABGin the Brazilian medical literature. Therefore, we describe this case to alert cardiovascular surgeons to the possibility of the occurrence of this kind of complication. We describe the anatomical basis that allows for its development, as well as suggestions for preventing and treating this condition, thus reducing possible damage to the patients.

Mailing address: Paulo Manuel Pêgo-Fernandes - Incor Av. Dr. Enéas C. Aguiar, $442^{\circ}$ - 05403-000 - São Paulo, SP

Received on $1 / 4 / 99$

Accepted on 4/14/99

\section{Case Report}

A 38-year-old male, with unstable angina, underwent cineangiocoronariography that showed severe coronary artery disease in the left anterior descending and left marginal arteries.

CABG was indicated and performed by median sternotomy on October 16, 1997. A saphenous vein graft was anastomosed to the left marginal branch and the internal thoracic artery to the left anterior descending artery. The early recovery was uneventful and the patient was discharged on day 5 after surgery. On January 12, 1998, the patient came back to the hospital reporting weight loss, weakness and dyspnea on mild exertion. On physical examination, a decreased vesicular murmur was observed.

A chest X-ray showed pleural effusion with opacification at the base of the left hemithorax (fig. 1). The patient was placed on a no-fat diet on the 2nd day. After 6 days, a puncture was made in the pleural sac and a milky material containing fat droplets was drained from the sac; a diagnosis of chylothorax was then made. The lungs did not expand well.

On the following day the patient underwent videothoracoscopy. Cleaning and pleural drainage were performed. On the first day, $250 \mathrm{ml}$ of liquid was drained from the posterior drain and $100 \mathrm{ml}$ from the anterior, averaging $105 \mathrm{ml} /$ day and $35 \mathrm{ml} /$ day, respectively, until the drains were removed.

Initially we used PPN and medium chain triglycerides (MCT) for ten days and leakage progressively decreased (fig. 2). After seven days of treatment, a low-fat diet was combined with PPN and MCT, administered three times a day for four days. During this period, the patient remained in good health condition, without fever and with a decrease in secretion shedding. PPN and MCT were withdrawn and the low-fat diet was maintained for additional four days, with a greater decrease in the leakage.

On February 3, 1998 leakage ceased. The anterior drain was removed and a global diet was started. On the following day, the posterior drain was removed and a control chest Xray was performed, where total regression of the process was observed (fig. 3). The patient was discharged on February 6, 1998, and, after several examinations, no recurrence of plural effusion was detected. 


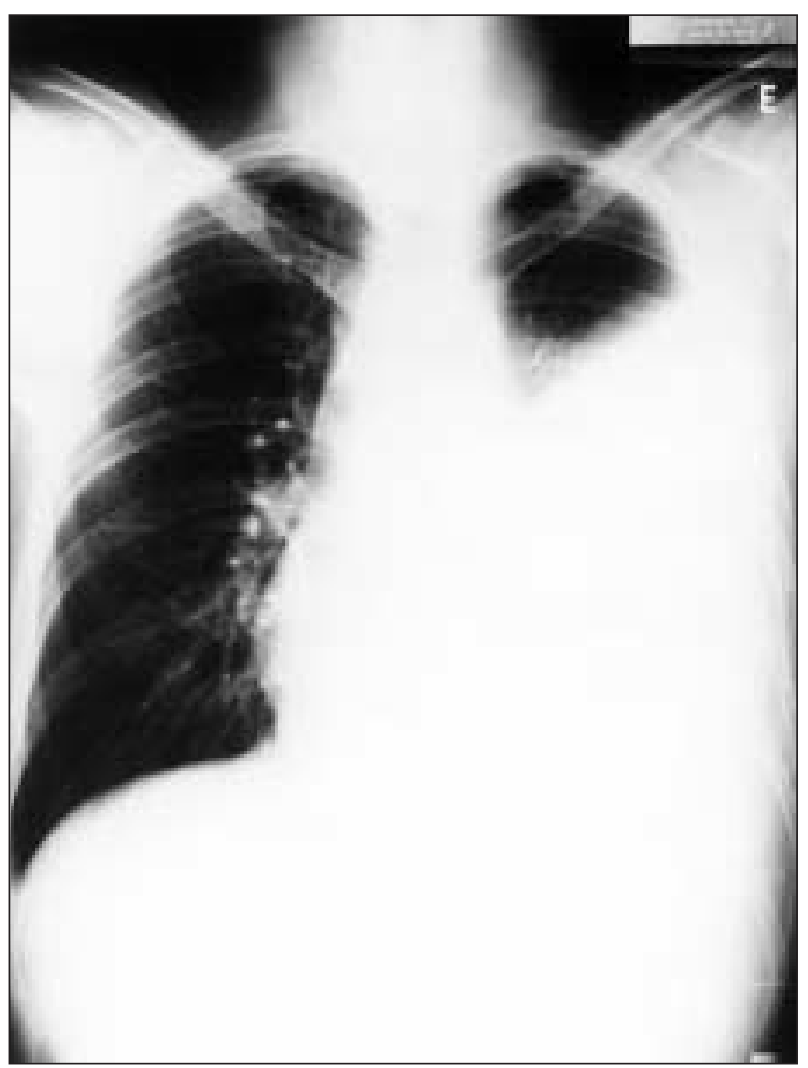

Fig 1 - Posterior-anterior chest film showing chylothorax with left-sided heavy pleural effusion.

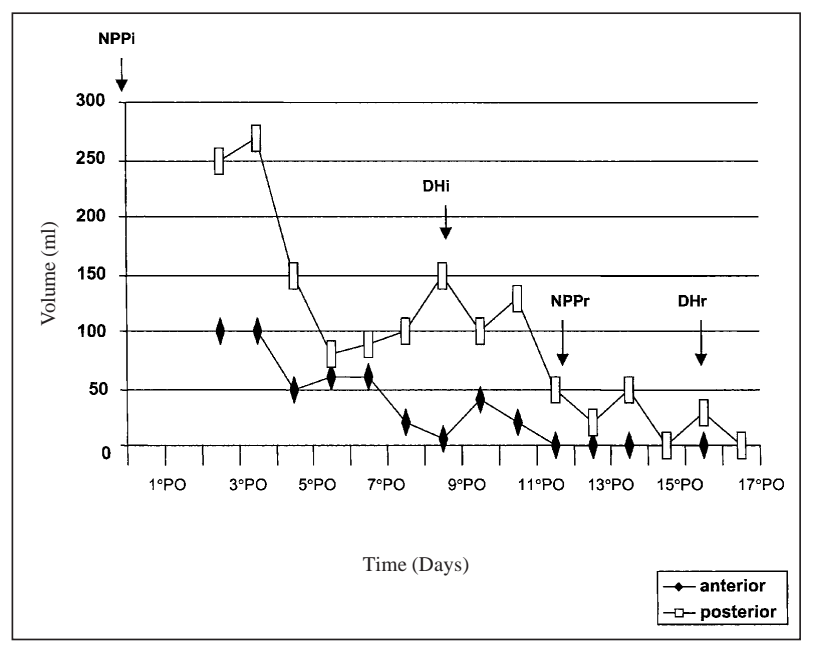

Fig. 2 - Anterior and posterior drainage between January 19, 1998 and February 4, 1998.

\section{Discussion}

There are many surgical interventions, such as cardiovascular, pleuropulmonary and mediastinal surgeries, among others, that may be followed by chylothorax.

In addition to ours, only ten other cases of chylothorax following $\mathrm{CABG}$ have been described in the medical literature 8 (table I), indicating that chylothorax is a rare complication of CABG with the left internal thoracic artery ${ }^{4-8}$.

The rarity of this complication can be explained by the lo-

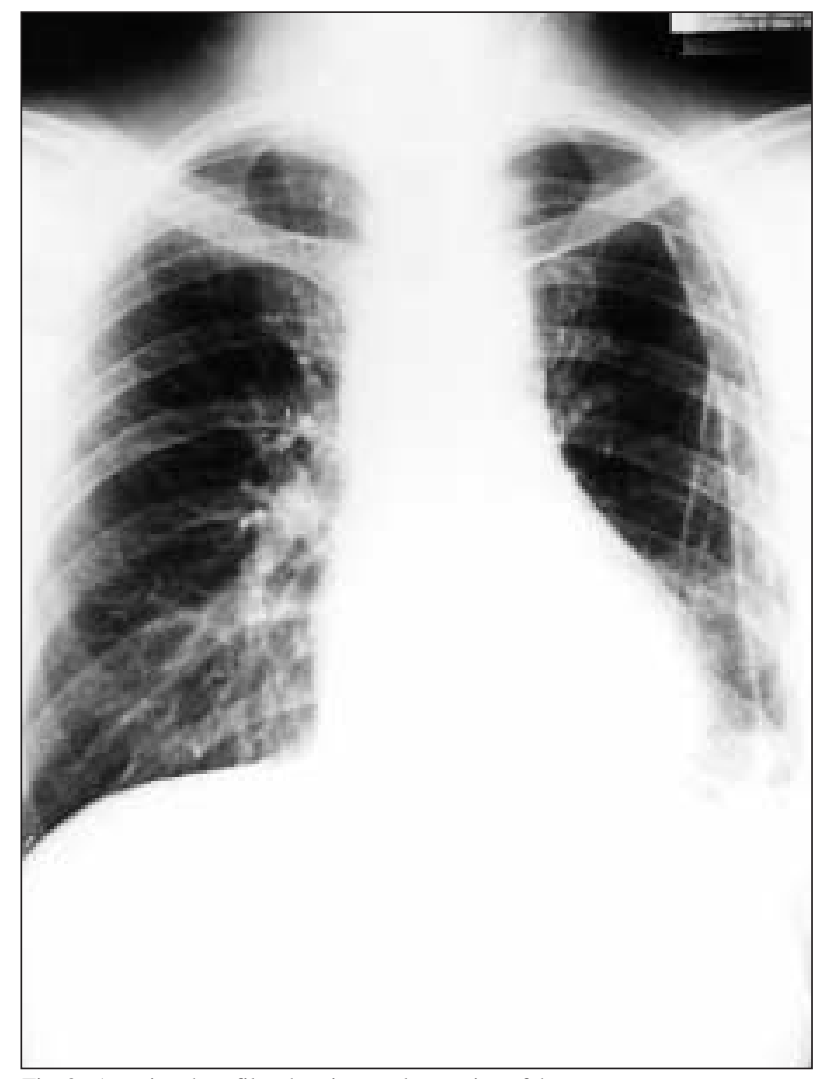

Fig. 3 - Anterior chest film showing total reversion of the process.

cation of the thoracic duct. The thoracic duct is located in the superior mediastinum, to the left of the posterior wall of the esophagus, close to the aortic arch and to the left subclavian artery. In the neck, it has a lateral ascending course and an inferior rotation behind the first portion of the left subclavian artery where it connects to the leftinternal jugular vein. During CABG, lymphatic channels may be disrupted in the region of the thymus or near the origin of the internal thoracic artery, which is taken out as part of the operative procedure.

However, this normal course of the thoracic duct is found in only half of the cases; the variable embryonic development causes 40 to $60 \%$ of the individuals to have two or more ducts ${ }^{4-8}$. Moreover, lymphatic collaterals end at the azygous, brachiocephalic, and intercostal veins, near the subclavian - jugular venous junction. Due to the great proximity of the lymphatic tributaries to the origin of the left internal thoracic artery, in part of the left subclavian artery, these lymphatics can be injured during manipulation. A thoracic duct pressure of 7.0 to $20.0 \mathrm{mmHg}$ was measured and may reflect in the pressure in the lymphatic tributaries, causing the chylous leak, if the vessel is damaged.

The cause of chylothorax is not known in many cases, as the conservative therapy can usually control the leakage successfully ${ }^{5,6}$.

There are a few cases where the origin of the leakage can be identified. For example, electrocauterization used in surgery damages primary lymphatics. Lymphatic control through suturing rather than through electro- 


\begin{tabular}{|lcccccc|}
\hline \multicolumn{7}{|c|}{ Table I - Reported cases in the literature of chylothorax as a complication of CABG through } \\
classical
\end{tabular}

cauterization is recommended as the latter produces hemostasis by the protein clot formation. As the lymph contains less cellular material and protein than the blood, this method, which is adequate for hemostasis, is less efficient in lymphatic control.

Chylothorax usually starts two to ten days after surgery, but the initial symptoms may appear only after weeks or months. In most cases, the diagnosis is not made until the patient starts a high-fat diet. Frequently, the drain is still in place when the adult patient begins oral intake of food, and an early diagnosis can be made, when the chyle becomes cloudy after the patient has eaten.

If an early diagnosis is not made, the first indication of chylothorax is initially seen as a mediastinum enlargement in the chest X-ray, and afterwards, as pleural effusion. Symptoms can be weight loss, loss of appetite and persistent low fever; although, in some cases, the patient is not seen until circulatory shock and severe respiratory distress have occurred. Hypoalbuminemia or hypoglobulinemia are usually found.

Thoracocentesis and milky fluid microscopical evaluation will reveal the presence of free fat. Fatty content will be higher in the milky fluid than in plasma, provided that protein content is around half of that in the plasma. Pancreatic lipase, amylase and deoxyribonuclease will be present

Because they reach the blood via thoracic duct. The main cellular component is represented by lymphocytes in

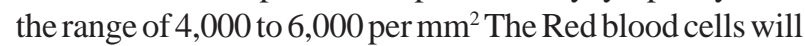

be in levels lower than 50 cells per $\mathrm{mm}^{2}$.

In cases diagnosed early, the initial management of chylothorax is usually conservative, ${ }^{2,4-9}$ and the main goals are to minimize chyle formation, to prevent the immune deficiency, and to maintain adequate drainage as well as to replace a high-fat diet with MCT, ${ }^{2,5,8}$ which are absorbed directly in the portal system without passing through the thoracic duct ${ }^{10,11}$. If the drainage remains high in spite of therapy, total parenteral nutrition must be indicated.

In these cases, surgical intervention will be considered only if there is incomplete drainage or continuous loss of chyle.

On the other hand, in cases like ours, where the postinterventional diagnosis of surgical chylothorax was delayed, a fibrinous clot and its adhesions made the search impossible. Even when the damaged duct is ligated, the possibility of leakage remains, either because of incomplete occlusion or due to the presence of other lymphatic channels. Pleurodesis is indicated in these cases ${ }^{13,14}$. In our patient, due to the inadequate lung expansion and to the late diagnosis, exploratory videothoracoscopy was used. Surgical adhesions made the duct exploration a high-risk procedure and, therefore, we opted for pleural cleaning and for pleurodesis.

In conclusion, prevention is the best method for avoiding chylothorax. It is a rare complication after CABG. In cases like ours, where the diagnosis was late, videothoracoscopy is extremely useful, because it is an efficient and less invasive method which allows for adequate pleurodesis. A careful diet is essential for a good clinical outcome. 


\section{References}

1. JateneFB, Bosisio IBJ, Jatene MB, etal. Quilotórax pós-traumático. Experiência no pós-operatório de cirurgia cardiotorácica. Arq Bras Cardiol 1993; 61: 229-32.

2. Joyce LD, Lindsay WG, Nicoloff DM. Chylothorax after median sternotomy for intrapericardial cardiac surgery. J Thorac Cardiovasc Surg 1976; 71: 476-80.

3. Cevese PG, Vecchioni R, Damico DF, et al. Postoperative chylothorax - Six cases in 2,500 operations, with a survey of the world literature. J Thorac Cardiovasc Surg 1975; 69: 966-71.

4. Di Lello F, Werner PH, Kleinman MD, Mullen DC, Flemma RJ. Life-threatenig chylothorax after left internal mammary artery dissection: therapeutic considerations. Ann Thorac Surg 1987; 44: 660-1.

5. Weber DO, Del Mastro P, Yarnoz MD. Chylothorax after myocardial revascularization with internal mammary graft. Ann Surg 1981; 32: 499-502.

6. Chaiyaroj S, Mullerworth MH, Tatoulis J. Surgery in the management of chylo- thorax after coronary artery bypass with left internal mammary artery. J Thorac Cardiovasc Surg 1993; 106: 754-6.

7. Kausel HW, Reeve TS, Stein AA, et al. Anatomic and pathologic studies of the thoracic duct. J Thorac Surg 1957; 34: 631.

8. Smith JA, Goldstein J, Oyer PE. Chylothorax complicating coronary artery bypass grafting. J Cardiovasc Surg 1994; 35: 307-9.

9. Baffes TG, Potts WJ. Postoperative chylothorax. Ann Surg 1954; 139: 501-5.

10. Frazer AC. Fat absorption and its disorders. Br Med Bull 1958; 14: 212.

11. Frazer AC. The mecanism of fat absorption. Biochem Soc Symp 1951; 9: 5.

12. Selle JG, Snyder WH, Schreiber .Chylothorax. Am J Surg 1960; 100: 8.

13. Hudspeth AS, Miller HS, Salem W. Isolated (primary) chylopericardium - Diagnosis and surgical treatment. J Thorac Cardiovasc Surg 1966; 51: 528-31.

14. Robinson CLN. The Management of chylothorax. Ann Thorac Surg 1985; 39: 90-5. 